\title{
Extraterrestrials Contact Human Beings: An Original Approach To Set The Authenticity of Alleged Close Encounters of The Fifth Kind
}

\author{
Julio Acosta-Navarro, Celso Bispo, Márcia Klimiuc, Fernanda Oliveira, Everaldo Ferreira, \\ Marisa Chueiri, Catarina Matteuzzi, Ivana Ribeiro, Moacyr Sampaio, José Maldonado
}

\begin{abstract}
In the past, the negative about the possibility of extraterrestrial intelligences coming into contact with the humankind was due to several factors, but at present, there is evidence from several fields challenging this mainstream. We hypothesized that authentic Close Encounters of Fifth Kind (CE5thK) could probably be happening. We designed and applied an original approach with qualitative and quantitative variables constituting a rule of 12 criterions for defining a high probability, low probability or inconclusive evidence in order to set the authenticity of 72 cases of alleged CE5thK. A high probability was considered as authentic. We found 47 cases to be low probability, none case to be inconclusive evidence and 25 cases to be high probability to be an authentic phenomenon. Using an original approach, we found evidence to support that advanced contact from ETI with human beings probably is happening on the Earth at present. Additionally in these authentic CE5thK cases, there are important and revolutionary information with amazing potential for our society in several fields of knowledge.
\end{abstract}

Index Terms - close encounters, extraterrestrial intelligence, new approach, unidentified flying object.

\section{INTRODUCTION}

Reports of seeing unidentified flying objects (UFOs) and beliefs that such objects are extraterrestrial spacecrafts have increased dramatically since World War II [1]. Thousands of UFOs are reported every year, usually to police, to the news media, or to UFO research groups. Roughly, $90 \%$ to $95 \%$ of all reported UFOs prove to be man-made aircraft or

Julio Acosta-Navarro, MD, PhD, PhD, Heart Institute, School of Medicine, São Paulo University, São Paulo, 05403-000, Brazil, Phone: 55-11-26615299

Celso Bispo, BSc, Past Affiliation - Faculdade OSEC, Universidade de Santo Amaro, São Paulo, 05862-200, Brazil.

Márcia Klimiuc, BSc, Past Affiliation - Faculdade de Filosofia, Letras e Ciências Humanas, Universidade de São Paulo, 05508-080, Brazil.

Fernanda Oliveira, Past Affiliation - ETEC- Parque da Juventude, São Paulo, 02030-100 Brazil.

Everaldo Ferreira, BSc, Past Affiliation - Universidade Paulista, Unidade Indianápolis, Engineering School, São Paulo, 04026-002, Brazil.

Marisa Chueiri, BSc, Past Affiliation - Universidade Paulista, Unidade Paraíso, Psychology School, São Paulo, 01504-000, Brazil.

Catarina Matteuzzi, Past Affiliation - ETEC-Prof. Camargo Aranha, São Paulo, 03169-040, Brazil. E-mail: catarina.mateuzzi@yahoo.com

Ivana Ribeiro, BSc, Past Affiliation - Escola Politécnica da Universidade de São Paulo, São Paulo, 01124-060, Brazil.

Moacyr Sampaio, BSc Past Affiliation - Instituto de Pesquisas Tecnológicas do Estado de São Paulo, São Paulo, 05508-901, Brazil.

José Maldonado, BSc, Past Affiliation - Instituto de Pesquisas de Energia Nuclear, São Paulo, 05508-000, Brazil unrecognized natural phenomenon. Approximately $1.5 \%$ to $2 \%$ are outright hoaxes, often accompanied by spurious photographs. Although hoaxes constitute such a small percentage of all UFO reports, they have created a disproportionate amount of trouble. Hoaxes are in fact, responsible for almost entirely disgracing the serious study of UFOs [2]. The remaining $3 \%$ to $8.5 \%$ of all UFOs sightings are those that appear to be aircraft of nonhuman origin.

In the past, the negative about of possibility of extraterrestrial intelligences (ETI) coming into contact with the humankind was due to several factors. At first, the presence of logical problems unsolved such as the Fermi Paradox, that is, the apparent contradiction between high estimates of the probability of the existence of ETI and the lack of evidence for, or contact with, such civilizations [3]. Second, the official reports from governmental agencies as the Condom Report [4], concluding that there was no evidence that UFOs were extraterrestrial spacecraft and that further study was not justified [5]. At third, the opinion by astronomers and other experts in the world $[6,7]$ published from the 70th-decade assuring the impossibility of that contact pointing out arguments of biological, geographical and technical nature. All these arguments could be considered polemic and present strong limitations.

There is evidence from several fields about the possibility of ETI could have entered into contact with the humankind challenging the mainstream of science that denies the possibility of this contact is happening. First, there is archeological and historical evidence suggesting the possibility that Earth was visited in ancient times by ETI. Ancient extraterrestrial theorists believe that, thousands of years ago, ETI landed on Earth where they were hailed as gods and helped shape human civilization [8]. Second, some researchers have reviewed the Fermi Paradox. Freitas affirmed that the assertion that ETI do not exist rests upon an unproven and untenable presumption: that ETI are currently not present in the Solar System [9]. The current observational status of the Solar System is insufficient to support the assumption that ETI are not here. Most advanced civilizations also would be either invisible or unrecognizable using current human observational methods, so millions of advanced societies may exist and still not be directly detectable by us Baum suggests that ETI intentionally hide from us and could be one scenario that would cause these objects to become difficult to locate and practically invisible [10]. They could have the capability of hiding from us given the likelihood of 
their superior technology, and there are many ways that ETI could remain undetected by us if it chooses to do so (the "Zoo Hypothesis"). In addition there is the conjectured possibility of making use of the additional dimensionalities of superstring and M-brane theory to transfer into adjacent universes where the speed of light limit may be quite different and reentering our universe at the desired location [11]. Furthermore, there is the high probability of contact expressed by the Drake equation [12] that is used to estimate the number of detectable ETI in the Milky Way galaxy. It is acknowledged that we have already announced our existence to any nearby technological civilizations and that not to anticipate contact with an ETI would be unwise. Finally, there are the reports of UFOs from qualified professionals and technical, including astronauts and official authorities [13].

In spite of these considerations, interest of the scientific community of testing the possibility of interaction of ETI with human beings on our planet has been almost non-existent. The few published scientific works have been concerned with psychological and psychiatric analysis of cases involving individuals allegedly abducted by ETI, usually for purpose of examination or experimentation, named Close Encounters of the Fourth Kind (CE4thK). According to studies, abduction narratives seem to proceed from internal sources, representing non-physical experiences of psychological origin inspired by publicized material, plus a significant number of hoaxes [14]. Studies concerning 'contactees' or people affirming have experimented a Close Encounters of Fifth Kind (CE5thK) defined as conscious contact with ETI with transmission of some information, are almost inexistent. Bartholomeu pointed out that although there are few psychological studies of 'contactees' or 'abductees', virtually all of these individuals have been characterized as mentally disturbed or irrational [15].

At present, it is unknown what is the meaning of the alleged CE5thK in relation to the possibility to be a real or authentic phenomenon. We hypothesized that authentic CE5thK could probably be occurring. The importance of testing this hypothesis could be revolutionary and would strongly influence other fields of human knowledge. Therefore, we studied several cases of alleged 'contactees' that publicly affirmed have had CE5thK with the objective of determine its authenticity. Secondly, if proved our hypotheses we would characterize the phenomenon.

\section{METHODS}

\section{A. Definition of CE5thK}

In order to understand better the UFO phenomenon, Hynek classified the cases of supposed contact with UFOs into three categories of Close Encounters [16]: Close Encounters of First Kind (CE1stK): Strange objects seen nearby but without physical interaction with the environment. Close Encounters of Second kind (CE2ndK): A CE1 case that leaves physical evidence, e.g. soil depressions, vegetation damage or causes electromagnetic interference. Close Encounters of Third kind (CE3rdK): CE1stK or CE2ndK cases where occupants or entities are seen.

After that, other researchers [17] defined the abduction phenomenon as CE4thK. 'Abductee' is someone kidnapped by ETI, usually for the purpose of examination and experimentation and often has a lapse of memory for the period they were held captive (missing time).

Finally, several writers defined the CE5thK [18], but the definitions were not concordant. Therefore, we defined for our study that CE5thK involves a more advanced contact of a witness named 'contactee' that consciously affirms to have contacted physical or mentally dialoguing and receiving transmission of some kind of information from ETI.

\section{B. The Final Contact Project}

The Final Contact Project was created by Dr. Acosta-Navarro in February 2008 in Sao Paulo, Brazil and aims to research alleged CE5thK. It began as personal work due to absence of funds from a public or official institution interested in this research. The initial data bank was made public in a ufologic meeting in April 2008 (Barueri, Brazil) and its first registered data was published in February 2009 [19]. Dr. Acosta-Navarro is a medical doctor holding a $\mathrm{PhD}$ degree in Medical Sciences and a second $\mathrm{PhD}$ degree in Social Sciences, both from the Sao Paulo University and has 35 years of experience in the ufology field having researched more than one hundred alleged CE5thK. After some time, a multidisciplinary team of professionals and technical with experience and interest in the field of ufology and correlated areas was engaged to carry out the research following the designed approach established by the Final Contact Project. This team was composed of 10 technical and professional in different areas of knowledge.

We used a purposive sampling. It was included in the study several cases of alleged CE5thK (non-science fiction or non-hoax at the preliminary evaluation) that met the followings inclusion criterions:

1. Availability of enough and trustable sources of information in order to arrive a definite conclusion.

2. Publicly known after 1947, the modern age of UFO.

Information obtained from primary sources of each alleged CE5thK has included face-to-face interviews or e-mail communications or when the alleged 'contactee' was dead, familial interviews or e-mail information. When it was possible, audio or video recording and transcriptions were used. Secondary sources included books, journals and websites were also used during the time this research was being conducted. The period of research applying the final design was from July 2011 until December 2014. The search for more information included travels of Dr. Acosta-Navarro to several cities of Brazil, Peru, México, Cuba, Argentina, Chile, USA, France, Germany and Italy.

\section{Design of study}

The design of the study was prospective, analytical and comparative and we considered as a quantitative and qualitative research. We had into account the checklist of consolidated criteria for reporting qualitative research (COREQ) [20]. The first step was establishing a set of valid criteria that should be used in order to set the authenticity of the alleged CE5thK because concept of truth is discussed and debated in several contexts, including philosophy and religion. Various theories and viewpoints of truth continue to 
be debated among scholars and philosophers [21]. We designed an original approach in order to set the truth or authenticity of each case. It was result from empirical knowledge coming from more than one hundred cases of alleged CE5thK in several decades of main researcher and adaptations of the classical criteria about how to establishing the truth.

The theoretical framework included the content analysis of information from alleged CE5thK to systematically organize data into a structured format. Each case was assigned and analyzed at least by two researchers. After each researcher had analyzed all the information available about each case independently, the case was presented to the team, debated and concluded in general meeting of experts. We emphasize the importance of more than one observer in order to lower at least the of experimenter bias.

The use of experts consensus as a tool to establishing the case authenticity is justified here due to absence of other kind of evidences. It is an accepted practice in other areas of knowledge as diagnosis and therapeutics medicine decisions. Frances believes this survey method is probably the best available means for standardizing practice for decisions points not well covered by research [22].

\section{Twelve criterions-rule}

It was built an evaluation tool containing qualitative and quantitative variables constituting a rule of twelve criterions to be applied to each case for defining if an alleged CE5thK has high probability (technically authentic or true) or low probability (technically non-auntenthic) of being authentic and thus lowering at the least the degree of subjectivity. The presence of any criterion gives a score of one point and its absence gives a score zero. The higher score increases the chances to get the cutoff threshold for being considered as high probability to be authentic.

The rationale of using an approach with criterions based in long empirical knowledge is accepted in other areas of knowledge as medicine, for example the criterion of Jones in order to diagnose Rheumatic Fever [23]. Subjective and objective criterions were set in the rule of twelve criterions as follow:

Subjective criterions:

1. Consistency. Absence of substantial contradictions in the description of the events and maintenance of the same story as a real experience during all the life of alleged 'contactee'.

2. Coherency/Logic of account. Fairness and transparency of the information and logic sequence of the reported story; all pertinent facts must be arranged in a consistent and cohesive fashion as an integrated whole.

3. Pragmatism. Disposition and facility of alleged 'contactee' in giving all the information related to events and no evidence suggesting elusive behavior avoiding specific details of reported story.

4. New contribution. Presence of information suggesting substantial new intellectual or scientific contribution in the content of story that was not probably created or originated from the abilities or knowledge of the alleged 'contactee'.

5. Sensorial perception. Experience involving objective and sensorial perception by any of the five senses and does not restricted exclusively to psychical-mental experiences from alleged 'contactee'.

6. Intuition /experience of researcher. Integral judgment facing the subjective and objective criterions and applying the experience and intuition of researcher for determining each case as authentic or not.

Objective criterions:

1. Presence of other witnesses in the main ufologic event.

2. Paranormality. Presence of any witnessed abnormal phenomena (telepathy, teletransport, telekinesis, clairvoyance, not explained curation or other).

3. Presence of physical evidence of the event as photography, films and other objects that analyzed by others researchers without indications of hoax.

4. Presence of body evidence as signs (injury, scar, burns or implants) other physical evidence (including implants) in the alleged 'contactee' resulting from contact.

5. Programmed contact of UFO phenomenon. It was valid if only the announcement prospective of a next contact was beforehand to others people including journalist, scientist of other witnesses of general public and that after was confirmed. We did not considered as valid if the account of a programmed contact was retrospective only and being the 'contactee' as the only witness.

6. Late scientific proof of any technical or historical information or technological device described by the alleged 'contactee' that after was confirmed, discovered or developed by the humankind later suggesting an advanced knowledge in relation to that date.

The researchers responsible for each case after the presentation and discussion of each alleged CE5thK case defined in mutual consensus what category the case should fall into. In the case of no consensus between two researchers, the case was reassigned to a third researcher in order to carrying out a new cycle of presentation and discussion in order to get a conclusion. The analysis for more than one observer had the objective of validating the findings of any individual observer.

\section{E. Definition of authenticity}

In order to define a case as "high probability" of being authentic (true) it was necessary that the case met all the six subjective criterions plus at least one objective criterion. We established this cutoff threshold because we considered that in the context of matter in discussion at present, we must choose the strictest level of cutoff in order to accept an alleged CE5thK as true beyond reasonable doubt. The six subjective criterions convinced to the researchers of authenticity of case and the presence of at least one objective criterion give the definite proof or worked as a way of internal validation. If a case had all the six criterions but none objective criterions we consider this as "inconclusive evidence". In order to define a case as "low probability" it was considered when the case presented five or less subjective criterions irrespective of the presence or absence of objective criterions.

In a second part of research it was planned a 
complementary analysis in the CE5thK cases concluded as high probability to be authentic. The characterization of theses authentic cases was based on questionnaire elaborated embracing different topics: 'contactee' data, ufologic events data, presence of information of historical, astronomical, physic-chemical, religious or philosophical, socio-economical, biological or the other nature. The processing of codes was based in this questionnaire.

\section{F. Ethics}

We did not consider necessary the informed consent of the alleged 'contactees' due to all these individuals had publicly assured having been contacted physically or mentally with an ETI and there was some information received from them, therefore this research is focused about a specific matter of public domain. Additionally some of alleged 'contactees' were not contacted by us directly and in others cases they were dead.

\section{G. Statistical analysis}

Statistical analysis and description of results were presented as absolute numbers and percentages. Categorical variables were summarized as percentages and continuous variables as mean \pm SD. The association between categorical variables was investigated by chi-square or Fisher exact tests. Statistical significance was assumed for $\mathrm{P} \leq 0.05$. All analyses were carried out using Stata 10 software (StataCorp LP, College Station, Texas).

\section{RESULTS}

\section{A. Descriptive analysis of total casuistic}

One hundred and two cases of alleged CE5thK from several locations of the world were initially identified and registered. From these, 30 cases were excluded by insufficient information sources and 72 cases were analyzed by two or more researchers and entered in the study (Figure 1).
It was found that the period when the cases were publicly known was between 1953 and 2011. Data about sex distribution, continent of origin, source of information, life-or-death situation and number of researchers by case are shown in Table1. In 72 alleges CE5thK there were three cases with two or more witnesses. There was predominance of men $(83.3 \%)$ and origin from South America (66.7\%). It was necessary the opinion of three or more researchers in $22.2 \%$ of cases.

\section{B. Categorization of authenticity}

Applying the approach and based on the 12 criterions-rule we tested the central hypotheses. The criterions scoring from each case identified by codename and country of origin are shown in Tables 2 and 3. It varied between 7 to 12 points for the cases of high probability (Table 2), six points for the cases with inconclusive evidence and 2 to 5 points for the cases of low probability to be authentic (Table 3). We found 47 cases to be low probability, none case to be inconclusive evidence and 25 cases were found to be high probability to be an authentic phenomenon (Figure 1). Our results suggest that probably true CE5thK is happening on the Earth.

\section{Brief description of two authentic CE5thK cases}

First case: RAMA (Perú)

Sixto Paz Wells, the main witness was born in Lima, Peru in 1955 and today is alive. In 1974, he had his first extraterrestrial contact -through telepathy, after attending a workshop offered by the Theosophical Society on that subject. Sixto received a psychographic message from an extraterrestrial called Oxalc who claimed to come from Ganymede, one of the moons of Jupiter. Doubtful of this extraordinary message, Sixto was ready to dismiss it but for another subsequent experiment with a group of friends.

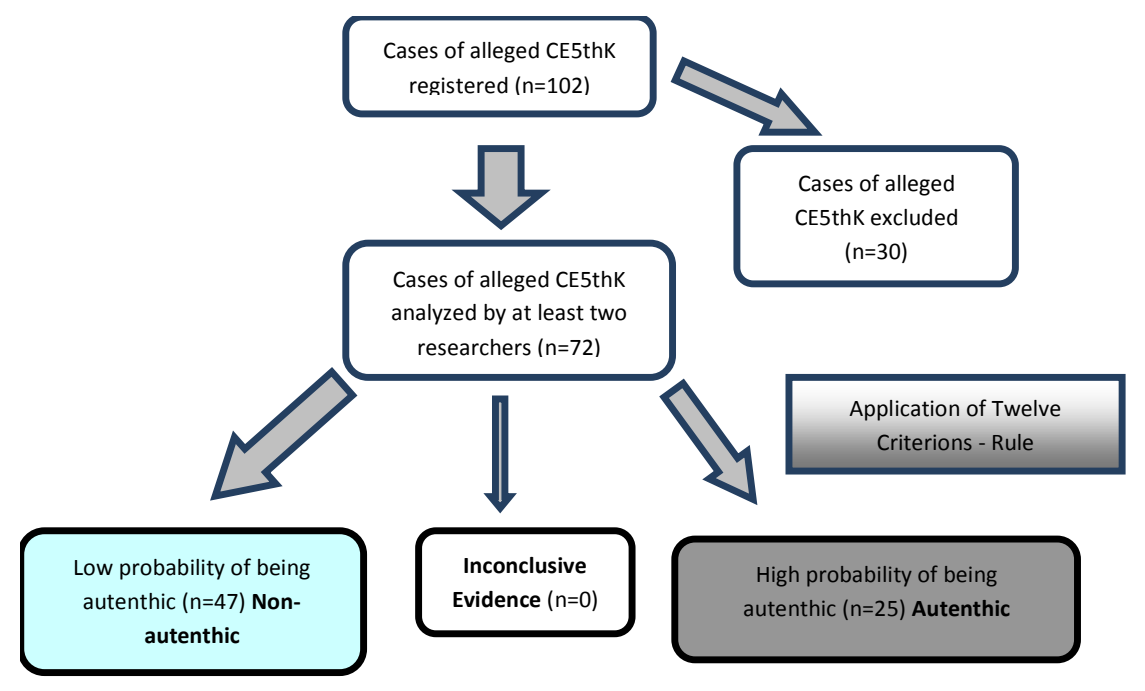

Figure 1: "Final Contact Project": Design of the study and main results. From 102 cases of alleged Close Encounters of Fifth Kind (CE5thK) registered, 30 cases were excluded by insufficient information. . "Low probability" of being authentic: the case met five or less subjective criterions irrespective of objective criterions presence; "Inconclusive evidence": the case met six subjective criterions and none objective criterion; "High probability" of being authentic: the case met all the six subjective criterions plus at least one objective criterion. 
On that fateful occasion, Oxalc invited them to a "pre-arranged encounter" to take place in the Chilca Desert - 60 kilometers south of Lima. In that day, they climbed a hill close to an abandoned mine and, although everyone was skeptical, several people went along with it and indeed, as witnesses even today insist, a large, metallic-looking, hamburger-shaped object came out of the Pacific Ocean (in front of the towns of Pucusana and Chilca) and approached them, flying closely overhead. As some of them became frightened they heard a voice saying that at that time there wouldn't be a landing or a physical contact because emotions in the group were running high. Then the object left. They were also told that there would be another opportunity to meet face to face. This encounter with UFO's took place on February 7, 1974 and was witnessed by 20 people [24].

Additional encounters followed, including ten well documented encounters that were witnessed by international journalists -who authenticated the extraterrestrial experience and their message of hope for humanity and our planet. The sightings involved multiple witnesses and the physical contacts involved a number of individuals who were being prepared for more extensive human extraterrestrial interactions. Sixto's case was independently investigated by the Spanish journalist Juan Benitez who was so impressed by the sightings and contacts that he wrote a number of books describing what was happening at Chilca, Peru [25].

There are also a number of photographs and films that have been taken of the UFO sightings by Sixto and Mission Rahma. The messages multiplied and the group grew, became international in scope and came to be known as "Misión Rama." The idea of living a simple, balanced and exemplary life of love and service, following the teachings of the great wisdom masters, was emphasized. Vegetarianism, the practice of daily meditation and of psychophysical or psycho energetic exercises was also suggested to prepare the body to the "vibrational shift" that meant having interaction with extraterrestrials. Nevertheless, none of these guidelines was ever forced upon participants [26]. The messages spoke of a dimensional shift, of reintegrating Earth to a different timeline and of imminent sweeping social, spiritual and historical changes. They partly reflected what seemed like a combination of theosophy with messianic Christianity. In addition, Sixto and other received information about the origin of the humanity and the influence of beings extraterrestrial that visited and colonized the Earth from different planets and star in the past. They provided an alternative history for humanity and a "mission": To work in several countries so as to awaken the sleeping consciousnesses of reincarnated individuals that had a commitment with this contact experience. Among the types of extraterrestrial beings Sixto has encountered: People coming from Ganymede, Venus and a planet of the star Alpha Centauri. Some of Sixto's most extraordinary extraterrestrial experiences include transportation through a xendra or inter-dimensional portal. On three occasions he affirmed has been inside spaceships. Sixto is a frequent speaker to the most prestigious world conferences in the subject of UFO's, and extraterrestrials. He has been invited to lecture at the United Nations in New York, La Sociedad de las Americas, Columbia University in New York, John F. Kennedy University in San Francisco and The Universidad Autonoma de Mexico among others [27]. Dr. Acosta-Navarro interviewed personally several times to Sixto Paz from 2011 until recently in February 2016.

We considered that this case met all the six subjective criterions of credibility: consistency, coherency/logic of account, pragmatism, new contribution, sensorial perception and intuition/experience of researcher. In addition, we concluded that this case met 04 objective criterions. Witnesses: several witnesses publicly affirmed have seen UFOs and had encounters with ETI. Paranormality was considered due to telepathy and teletransportantion in several opportunities. Physical evidence was considered by photographies taken by different people including independent journalists. Programmed contact was the more strong evidence because this happened in more than ten times with invitation of national and international journalist and technical and professional people with publication in newspaper and media programs. Score: 10 .

Table 1: Descriptive data from alleged CE5thK as a whole $(\mathbf{n}=72)$

\begin{tabular}{|c|c|c|}
\hline \multirow[t]{2}{*}{ General data } & Subcategor & Percentage of \\
\hline & $\mathbf{y}$ & total \\
\hline \multirow[t]{2}{*}{$\operatorname{Sex}(n=74) *$} & Male & $60(83.3 \%)$ \\
\hline & Female & $14(16.7 \%)$ \\
\hline \multirow{7}{*}{$\begin{array}{c}\text { Continent } \\
\text { origin }(n=72)\end{array}$} & South & $48(66.7 \%)$ \\
\hline & America & \\
\hline & North & $14(19.4 \%)$ \\
\hline & America & \\
\hline & Europe & $8(11.1 \%)$ \\
\hline & Asia & $1(1.4 \%)$ \\
\hline & Africa & $1(1.4 \%)$ \\
\hline Source & Primary & $33(45.8 \%)$ \\
\hline
\end{tabular}

information

$(n=72)$

$\begin{array}{cll} & \text { Secondary } & 39(54.2 \%) \\ \begin{array}{c}\text { Life-or-death } \\ \text { situation }(\mathrm{n}=74) *\end{array} & \text { Alive } & 40(54.1 \%) \\ & & \\ & \text { Death } & 26(35.1 \%) \\ \text { Researchers by } & \text { Unknown } & 8(10.8) \\ & \text { Two } & 56(77.8 \%)\end{array}$

case $(n=72)$

Three or $16(22.2 \%)$

more

CE5thK: Close Encounter of the Fifth Kind

*In 72 cases of alleged CE5thK there were three cases with two main witnesses each one. In one case from these, we have not all information from all witnesses. 
Table 2. Scoring of CE5thK cases with high probability of being authentic $(n=25)$

\begin{tabular}{|c|c|c|c|c|c|c|c|c|c|c|c|c|c|c|c|}
\hline CASE & COUNTRY & $\mathrm{SC} 1$ & $\mathrm{SC} 2$ & SC3 & $\mathrm{SC} 4$ & SC5 & SC6 & $\mathrm{OC} 1$ & OC2 & OC3 & OC4 & OC5 & OC6 & SCORE & CATEGORY \\
\hline DCC & Peru & 1 & 1 & 1 & 1 & 1 & 1 & 1 & 1 & 1 & 1 & 1 & 1 & 12 & HP \\
\hline GiBo & Italy & 1 & 1 & 1 & 1 & 1 & 1 & 0 & 1 & 1 & 1 & 0 & 1 & 10 & HP \\
\hline Meier & Switzerland & 1 & 1 & 1 & 1 & 1 & 1 & 1 & 1 & 1 & 0 & 0 & 1 & 10 & HP \\
\hline RAMA & Peru & 1 & 1 & 1 & 1 & 1 & 1 & 1 & 1 & 1 & 0 & 1 & 0 & 10 & HP \\
\hline Rá & Brazil & 1 & 1 & 1 & 1 & 1 & 1 & 1 & 1 & 1 & 1 & 0 & 0 & 10 & HP \\
\hline Ur-G & Israel & 1 & 1 & 1 & 1 & 1 & 1 & 1 & 1 & 1 & 0 & 0 & 1 & 10 & HP \\
\hline G-Adam & USA & 1 & 1 & 1 & 1 & 1 & 1 & 1 & 0 & 1 & 0 & 0 & 1 & 9 & HP \\
\hline Karran & Brazil & 1 & 1 & 1 & 1 & 1 & 1 & 1 & 1 & 0 & 0 & 1 & 0 & 9 & HP \\
\hline UMM & Spain & 1 & 1 & 1 & 1 & 1 & 1 & 1 & 0 & 1 & 0 & 0 & 1 & 9 & HP \\
\hline A-Omeg & Chile & 1 & 1 & 1 & 1 & 1 & 1 & 0 & 1 & 0 & 0 & 0 & 1 & 8 & HP \\
\hline Charli & Brazil & 1 & 1 & 1 & 1 & 1 & 1 & 1 & 0 & 1 & 0 & 0 & 0 & 8 & HP \\
\hline Duclt & Argentina & 1 & 1 & 1 & 1 & 1 & 1 & 1 & 0 & 0 & 0 & 1 & 0 & 8 & HP \\
\hline AAF & Brazil & 1 & 1 & 1 & 1 & 1 & 1 & 0 & 1 & 0 & 1 & 0 & 0 & 8 & HP \\
\hline Rincón & Colombia & 1 & 1 & 1 & 1 & 1 & 1 & 1 & 0 & 0 & 0 & 1 & 0 & 8 & HP \\
\hline E-Sirg & Italy & 1 & 1 & 1 & 1 & 1 & 1 & 0 & 1 & 1 & 0 & 0 & 0 & 8 & HP \\
\hline S-Vill & Mexico & 1 & 1 & 1 & 1 & 1 & 1 & 0 & 0 & 1 & 0 & 0 & 1 & 8 & HP \\
\hline VlaK & Peru & 1 & 1 & 1 & 1 & 1 & 1 & 1 & 0 & 0 & 0 & 0 & 1 & 8 & HP \\
\hline Berlet & Brazil & 1 & 1 & 1 & 1 & 1 & 1 & 0 & 0 & 0 & 0 & 0 & 1 & 7 & HP \\
\hline $\mathrm{D}-\mathrm{Fr}$ & USA & 1 & 1 & 1 & 1 & 1 & 1 & 0 & 0 & 0 & 0 & 0 & 1 & 7 & $\mathrm{HP}$ \\
\hline E-Klar & Southafrica & 1 & 1 & 1 & 1 & 1 & 1 & 0 & 1 & 0 & 0 & 0 & 0 & 7 & HP \\
\hline D-Krasp & Brazil & 1 & 1 & 1 & 1 & 1 & 1 & 0 & 0 & 0 & 0 & 0 & 1 & 7 & HP \\
\hline Mags & Canada & 1 & 1 & 1 & 1 & 1 & 1 & 0 & 0 & 0 & 0 & 0 & 1 & 7 & HP \\
\hline Profesor & Brazil & 1 & 1 & 1 & 1 & 1 & 1 & 0 & 0 & 0 & 0 & 1 & 0 & 7 & HP \\
\hline Rossi & Brazil & 1 & 1 & 1 & 1 & 1 & 1 & 0 & 0 & 0 & 0 & 0 & 1 & 7 & HP \\
\hline A-Tas & Brazil & 1 & 1 & 1 & 1 & 1 & 1 & 0 & 0 & 0 & 1 & 0 & 0 & 7 & HP \\
\hline
\end{tabular}

CE5thK: Close Encounter of the Fifth Kind; HP: High probability to be authentic; IE: Inconclusive evidence; LP: Low probability to be authentic; OC: Objective criterion; SC: Subjective criterion; SC1: Consistency; SC2: Coherency/Logic; SC3: Pragmatism; SC4: New contribution; SC5: Sensorial perception; SC6: Intuition/Experience; OC1: Other witnesses; OC2: Paranormality; OC3: Physical evidence; OC4: Body evidence; OC5: Programmed contact; OC6: Scientific proof.

Table 3. Scoring of CE5thK cases with low probability of being authentic (n=47)

\begin{tabular}{lllllllllllllllllll}
\hline CASE & COUNTRY & SC1 & SC2 & SC3 & SC4 & SC5 & SC6 & OC1 & OC2 & OC3 & OC4 & OC5 & OC6 & SCORE CATEGORY \\
\hline CoInz & Brazil & 1 & 1 & 1 & 1 & 1 & 0 & 0 & 0 & 0 & 0 & 0 & 0 & 5 & LP & \\
Pmo & France & 1 & 1 & 1 & 1 & 1 & 0 & 0 & 0 & 0 & 0 & 0 & 0 & 5 & LP & \\
Pasch & Brazil & 1 & 1 & 1 & 1 & 1 & 0 & 0 & 0 & 0 & 0 & 0 & 0 & 5 & LP & & \\
HeMa & Brazil & 1 & 1 & 1 & 1 & 0 & 0 & 0 & 0 & 0 & 0 & 0 & 1 & 5 & LP & \\
RVG & Peru & 1 & 1 & 1 & 1 & 1 & 0 & 0 & 0 & 0 & 0 & 0 & 0 & 5 & LP & \\
Ebo & Brazil & 1 & 1 & 0 & 1 & 1 & 0 & 0 & 0 & 0 & 0 & 0 & 0 & 4 & LP \\
Pha & Mexico & 1 & 1 & 0 & 1 & 1 & 0 & 0 & 0 & 0 & 0 & 0 & 0 & 4 & LP \\
JaVE & Brazil & 1 & 1 & 1 & 1 & 0 & 0 & 0 & 0 & 0 & 0 & 0 & 0 & 4 & LP \\
LGS & Brazil & 1 & 1 & 1 & 1 & 0 & 0 & 0 & 0 & 0 & 0 & 0 & 0 & 4 & LP \\
MoM & Brazil & 1 & 1 & 0 & 1 & 1 & 0 & 0 & 0 & 0 & 0 & 0 & 0 & 4 & LP \\
TeB & USA & 1 & 1 & 1 & 1 & 0 & 0 & 0 & 0 & 0 & 0 & 0 & 0 & 4 & LP \\
Trig & Brazil & 1 & 1 & 1 & 1 & 0 & 0 & 0 & 0 & 0 & 0 & 0 & 0 & 4 & LP \\
DoY & Brazil & 1 & 1 & 1 & 1 & 0 & 0 & 0 & 0 & 0 & 0 & 0 & 0 & 4 & LP \\
DFr & Argentina & 1 & 1 & 0 & 0 & 1 & 0 & 0 & 0 & 0 & 0 & 1 & 0 & 4 & LP
\end{tabular}




\begin{tabular}{|c|c|c|c|c|c|c|c|c|c|c|c|c|c|c|c|}
\hline $\mathrm{AbS}$ & México & 1 & 1 & 1 & 0 & 0 & 0 & 0 & 0 & 0 & 0 & 0 & 0 & 3 & LP \\
\hline $\mathrm{BM}$ & USA & 1 & 1 & 0 & 1 & 0 & 0 & 0 & 0 & 0 & 0 & 0 & 0 & 3 & LP \\
\hline Bilu & Brazil & 1 & 1 & 0 & 0 & 1 & 0 & 0 & 0 & 0 & 0 & 0 & 0 & 3 & LP \\
\hline ACQ & Peru & 1 & 1 & 0 & 0 & 1 & 0 & 0 & 0 & 0 & 0 & 0 & 0 & 3 & LP \\
\hline DiamF & Brazil & 1 & 1 & 0 & 1 & 0 & 0 & 0 & 0 & 0 & 0 & 0 & 0 & 3 & LP \\
\hline $\mathrm{NaG}$ & Italy & 0 & 1 & 0 & 1 & 1 & 0 & 0 & 0 & 0 & 0 & 0 & 0 & 3 & LP \\
\hline BHC & USA & 1 & 1 & 0 & 1 & 0 & 0 & 0 & 0 & 0 & 0 & 0 & 0 & 3 & LP \\
\hline $\mathrm{LC}$ & USA & 1 & 1 & 0 & 1 & 0 & 0 & 0 & 0 & 0 & 0 & 0 & 0 & 3 & LP \\
\hline Maranguap & Brazil & 1 & 1 & 0 & 0 & 1 & 0 & 0 & 0 & 0 & 0 & 0 & 0 & 3 & LP \\
\hline MeTy & USA & 1 & 1 & 0 & 1 & 0 & 0 & 0 & 0 & 0 & 0 & 0 & 0 & 3 & LP \\
\hline $\mathrm{ChM}$ & Brazil & 1 & 1 & 0 & 0 & 1 & 0 & 0 & 0 & 0 & 0 & 0 & 0 & 3 & LP \\
\hline Rbu & Colombia & 1 & 1 & 0 & 1 & 0 & 0 & 0 & 0 & 0 & 0 & 0 & 0 & 3 & LP \\
\hline Ral & France & 1 & 1 & 0 & 0 & 1 & 0 & 0 & 0 & 0 & 0 & 0 & 0 & 3 & LP \\
\hline $\mathrm{SiS}$ & Brazil & 1 & 1 & 0 & 1 & 0 & 0 & 0 & 0 & 0 & 0 & 0 & 0 & 3 & LP \\
\hline DKM & USA & 1 & 1 & 0 & 1 & 0 & 0 & 0 & 0 & 0 & 0 & 0 & 0 & 3 & LP \\
\hline Zoh & USA & 1 & 1 & 0 & 1 & 0 & 0 & 0 & 0 & 0 & 0 & 0 & 0 & 3 & LP \\
\hline KrAn & Brazil & 1 & 1 & 0 & 0 & 0 & 0 & 0 & 0 & 0 & 0 & 0 & 0 & 2 & LP \\
\hline Conde & Brazil & 1 & 1 & 0 & 0 & 0 & 0 & 0 & 0 & 0 & 0 & 0 & 0 & 2 & LP \\
\hline Dora & Brazil & 1 & 1 & 0 & 0 & 0 & 0 & 0 & 0 & 0 & 0 & 0 & 0 & 2 & LP \\
\hline Erg & Brazil & 1 & 1 & 0 & 0 & 0 & 0 & 0 & 0 & 0 & 0 & 0 & 0 & 2 & LP \\
\hline Guard & Argentina & 1 & 1 & 0 & 0 & 0 & 0 & 0 & 0 & 0 & 0 & 0 & 0 & 2 & LP \\
\hline Yosip & Peru & 0 & 1 & 0 & 1 & 0 & 0 & 0 & 0 & 0 & 0 & 0 & 0 & 2 & LP \\
\hline Al-Mad & Brazil & 1 & 1 & 0 & 0 & 0 & 0 & 0 & 0 & 0 & 0 & 0 & 0 & 2 & LP \\
\hline MarLo & Brazil & 1 & 1 & 0 & 0 & 0 & 0 & 0 & 0 & 0 & 0 & 0 & 0 & 2 & LP \\
\hline JLMar & Brazil & 1 & 1 & 0 & 0 & 0 & 0 & 0 & 0 & 0 & 0 & 0 & 0 & 2 & LP \\
\hline $\mathrm{ChP}$ & Brazil & 1 & 1 & 0 & 0 & 0 & 0 & 0 & 0 & 0 & 0 & 0 & 0 & 2 & LP \\
\hline $\mathrm{RM}$ & USA & 1 & 1 & 0 & 0 & 0 & 0 & 0 & 0 & 0 & 0 & 0 & 0 & 2 & LP \\
\hline Srta & México & 1 & 1 & 0 & 0 & 0 & 0 & 0 & 0 & 0 & 0 & 0 & 0 & 2 & LP \\
\hline SeShan & Brazil & 1 & 1 & 0 & 0 & 0 & 0 & 0 & 0 & 0 & 0 & 0 & 0 & 2 & LP \\
\hline RoR & Chile & 1 & 1 & 0 & 0 & 0 & 0 & 0 & 0 & 0 & 0 & 0 & 0 & 2 & LP \\
\hline Terrão & Brazil & 0 & 1 & 0 & 1 & 0 & 0 & 0 & 0 & 0 & 0 & 0 & 0 & 2 & LP \\
\hline $\operatorname{TrG}$ & Germany & 1 & 1 & 0 & 0 & 0 & 0 & 0 & 0 & 0 & 0 & 0 & 0 & 2 & LP \\
\hline Zoca & Brazil & 1 & 1 & 0 & 0 & 0 & 0 & 0 & 0 & 0 & 0 & 0 & 0 & 2 & LP \\
\hline
\end{tabular}

CE5thK: Close Encounter of the Fifth Kind; HP: High probability to be authentic; IE: Inconclusive evidence; LP: Low probability to be authentic; OC: Objective criterion; SC: Subjective criterion; SC1: Consistency; SC2: Coherency/Logic; SC3: Pragmatism; SC4: New contribution; SC5: Sensorial perception; SC6: Intuition/Experience; OC1: Other witnesses; OC2: Paranormality; OC3: Physical evidence; OC4: Body evidence; OC5: Programmed contact; OC6: Scientific proof. 


\section{Second case: KARRAN (Brazil)}

The witnesses Hermínio Reis and Bianca de Oliveira are of Minas Gerais. She is a simple housewife, basic education and she is alive. He was an evangelical Minister and dead in 2013. According to the report made by them, its fantastic experience started on the night of January 12, 1976, around 18:00 hours, when they left the Rio de Janeiro, where he resided at the time, heading to Belo Horizonte, for a short trip. When were already in Minas Gerais, near the city of Matias Barbosa, decided to stop the car, on the side of a stretch of highway that had not yet been opened, Herminio decided to rest a little and went to sleep, Bianca was awake and attentive. Approximately 23:00 hours, looking at the horizon, she noticed a light moving from one side to another, at first thought it was a balloon, featured a light intensely Orange, but suddenly she realized that the object was in and out of the clouds. At first, the object seemed to be distant, but at one moment seemed to disappear from your sight off very close to looking like reappearing was going to fall on the car. Bianca began to scream: "Herminio, Herminio, a plane is falling on our heads", Hermínio woke up, but could do nothing, because at the moment all had dimmed to the point that they don't see themselves. Without know how, the UFO sucked the car inside, leading the couple together. Then the artifact took flight and entered into another ship, when the couple was finally pulled from the car and driven for two people, where you can see several other ships stationed. Soon after, were led to a place where there were a few seats where they sat. Two men of great stature, around 2 metres, approached the vehicle with smile on her face, and cordially helped us get out of the car. After calm down, because it had had a major panic attack, Bianca e Hermínio followed the men who led to a kind of elevator arriving in another room, like a lab. The extraterrestrial beings were similar, as if they were twins, and talked to each other, they had a long talk with Bianca and Herminio, through a device like a kind of helmet with many wires, which functioned as a translator [28].

In this conversation, the caller introduced himself as Karran, from the planet Klemer, a celestial body too far away and unknown by earthlings. In this dialogue, they talked about religion, contacts between humans and these beings and the creation of man, as well as other philosophical and mystical issues [29]. After a time of conversation the ETs offered a kind of soft bread but no taste, and a kind of serum. At the end of the conversation, Karran recorded brain waves of Bianca in order to get in touch later, then offered a green liquid to your guests saying it was for them to forget what happened, but Bianca asked for them not to do that, and your request was kindly answered. In the information received by Hermínio and Bianca were clear references to the spiritual nature of man and the universe in which we and they live. Stunning detail on the origin of humanity were also transmitted to the contactees. For example, second would have been told by Karran, civilizations inhabiting other worlds already visiting Earth since remote times. He told Hermínio and Bianca that our planet once was plant and animal life, but of a lower type. Thus, such civilizations would have studied the Earth's climate, its environmental conditions and geological features in general, coming to the conclusion that the Earth would have favorable conditions to go through a process of colonization, as well as other worlds that were also being visited [30]. They told them that in Klermer the people are one race and live as one family. There are no wars, division by countries or money in the social organization. Two days after being kidnapped, the couple was left inside the vehicle on a dirt road not far from the place where it all began. Dr. Acosta-Navarro interviewed personally Herminio Reis in 2011.

We considered that this case met all the six subjective criterions of credibility: consistency, coherency/logic of account, pragmatism, new contribution, sensorial perception and intuition/experience of researcher. In addition, we concluded that this case met 03 objective criterions. Witnesses: Two witnesses publicly affirmed all the experience of advanced contact. Paranormality was considered due to telepathy and teletransportantion from Matias Barbosa and Conselheiro Lafaite city to $200 \mathrm{~km}$ of distance and an account of curation of neurologic condition of Bianca's father when a contact with an UFO. Programmed contact was considered because after the first contact Bianca received communication in advance in two opportunities to encounters Karran with other witnesses. Score: 09.

\section{Information from the authentic CE5thK cases}

The second objective was the characterization and analysis of information from CE5th cases with high probability to be authentic. In three cases there were more than two witnesses in the contact phenomenon and in one of these cases the information regarding the sex of all the witnesses was absent. From 27 authentic 'contactees', there was predominance of men compared with women ( 25 vs. 2 respectively) and when compared with CE5thK cases of low probability (35 vs. 12 respectively) this difference was not significant $(\mathrm{P}=0.055)$. The age mean was $33.74 \pm 3.29$ y and the first contact happened through infancy to middle adulthood. The youngest age was $4 \mathrm{y}$ and the oldest $62 \mathrm{y}$. The CE5thK is a world phenomenon as several continents originated of cases mainly South America (60.0\%). The rate of immigrants was $40.7 \%$ (Table 4).

The authentic 'contactees' had not substantial knowledge about them, because geographical distances, language different and some cases were not contemporaries and this fact permitted to do additional test in order to search consistence among them or to find any possible interrelations among them.

The physical description of ETI (96.0\%) or physical description of a spacecraft $(100 \%)$, like as telepathic manifestation (100\%) was present in almost all the cases. The number of encounters of two or more times was present in $84.0 \%$ of cases.

The communication in all the authentic cases were bidirectional and happened by oral, mental and by other way (helmet in one case). The 'contactee' or 'contactees' were conscious in the experience and the dialogue happened. With respect to the questions, it differed from the witnesses, the context of experience of contact and the nature and precedence of ETI. In general, the questions were more frequents from the human beings and the answers from ET beings from questions of human beings account for the volume of information in fields of history, scientific theories, religion and philosophy. It was informed that the origin of 
ETI were different, including different planets or satellites from our System Sun, other constellation in our galaxy, other galaxies, other dimensions and unknown origin.

Table 4: Descriptive data from authentic CE5thK $(n=25)$

\begin{tabular}{|c|c|c|}
\hline General data & Subcategory & Percentage of total \\
\hline \multirow[t]{2}{*}{$\operatorname{Sex}(n=27) *$} & Male & $25(92.6 \%)$ \\
\hline & Female & $2(7.4 \%)$ \\
\hline \multirow[t]{3}{*}{ Age group of first event $(n=27) *$} & $\begin{array}{l}\text { Children or Adolescent (until } \\
19 \mathrm{y})\end{array}$ & $6(22.2 \%)$ \\
\hline & Young adult (20-40 y) & $9(33.3 \%)$ \\
\hline & Middle adult (41-64 y) & $12(44.5 \%)$ \\
\hline \multirow[t]{5}{*}{ Continent of origin $(n=25)$} & South America & $15(60.0 \%)$ \\
\hline & North America & $4(16.0 \%)$ \\
\hline & Europe & $4(16.0 \%)$ \\
\hline & Asia & $1(4.0 \%)$ \\
\hline & Africa & $1(4.0 \%)$ \\
\hline \multirow[t]{2}{*}{ Immigrant $(\mathrm{n}=27) *$} & Yes & $11(40.7 \%)$ \\
\hline & Not & $16(61.5 \%)$ \\
\hline \multirow[t]{2}{*}{ Source of information $(n=25)$} & Primary & $12(48.0 \%)$ \\
\hline & Secondary & $13(52.0 \%)$ \\
\hline \multirow[t]{3}{*}{ Life-or-death situation $(\mathrm{n}=27 *$} & Alive & $8(29.6 \%)$ \\
\hline & Death & $16(59.3 \%)$ \\
\hline & Unknown & $3(11.1 \%)$ \\
\hline \multirow[t]{2}{*}{ Number of researchers by case $(n=25)$} & Two & $11(44.0 \%)$ \\
\hline & Three or more & $14(56.0 \%)$ \\
\hline
\end{tabular}

\section{CE5thK: Close Encounter of the Fifth Kind}

*In 24 cases of authentic CE5thK cases there were three cases with two main witnesses each one. In one case from these cases, we have not all information from witnesses.

The motivations of ETI visiting Earth informed by them were: study or exploration mission, alert to humankind, nuclear hazard and awakening consciousness as presented in Table 5. The majority of these cases had the information of more than one motivation at the same time.

The presence of information about different topics in most of cases permitted to analyze specific information. There was a significant concordance in these categorical specific variables: "vegetarianism as pattern recommended" (vegetarianism), "critics-to-capitalism or money-based system" (money-critics), "reincarnation as real and existent phenomenon" ("reincarnation") and "assurance of presence of ETI living among us" (ETI among us) (Table 5).

"Vegetarianism" was found to be in $16(84.2 \%)$ out 19 authentic CE5thK cases with available information. On the contrary, in three cases it was permitted consumption of meat (two cases was fish). When we compared with our population affirming be vegetarian and using as reference Brazil data $(8 \%)$ [31], considering the lack of world-wide data, we observed a significant lower practice of this lifestyle in our planet $(\mathrm{P}<0.001)$.

"Money-critics" was present in all 18 cases (100\%) with information available. On the contrary, none case recommended or justified this economic model. When we compared this with our population's living under non-capitalist or socialist regime and we utilized China, Vietnam, North Korea, Laos and Cuba as a reference with $21.03 \%$ of world population [32] we also observed a lower practice of non-capitalist system in our planet $(\mathrm{P}<0.001)$.

"Reincarnation" as real and existent phenomenon was present in all 12 cases $(100 \%)$ with available information. None of the cases had any information denying this phenomenon. When compared with our population believing in the reincarnation and using as reference the population under reincarnationist religions as Hinduism and Buddhism with $22.1 \%$ of the world's population [33] we again observed a significant lower rate of peoples living with this belief $(\mathrm{P}<0.001)$.

The assurance of presence of ETI living among us was found in all 15 cases $(100 \%)$ with available information. In none of these cases it was denied.

\section{DISCUSSION}

Using an original approach we found evidence to support that some cases of alleged CE5thK has a high probability of authenticity to be true advanced contact of ETI with human beings on the Earth. At our knowledge, this is the first time in the world reporting this kind of findings and our results are in counter flow of mainstream of science and astronomy challenging the paradigm of impossibility of mankind have contacted with ETI.

Additionally in these authentic CE5thK cases, there is some important information with amazing potential for our society in several fields of knowledge. By other hand, we found that the most of alleged CE5thK, two thirds of all cases, to be low probability of authentic phenomenon.

The use our design with more than one observer and an original 12-criterion standard is utilized in order to consider an alleged CE5thK as authentic or not, is justified in the absence of additional studies in the respective field. As we know, the truth in science is probabilistic and not absolute. Our studied phenomenon is more similar to legal and social subjects than a biological or physical phenomenon.

The cases of high probability we considered technically authentic. Although we observed a phenomenon that we called "contamination", where in true advanced contact, some 
information received by the 'contactee' from ETI and provided to the public could not be absolutely precise and exact due to difficulty in recalling details of the experience. The matter in discussion here is restricted to the possibility of advanced contact with ETI at least one time in any case. Additionally, a phenomenon similar but in opposite sense would be perceived in the group "low probability" that we called "reverse contamination" when valid or correct information from abilities or knowledge from non-authentic 'contactees' complemented a non-real advanced contact with ETI with the objective to give more credibility to their accounts.

The deep analysis within the authentic CE5thK cases revealed interesting information of religious, philosophical, social, biological and technical nature. The predominance of men as authentic 'contactees' leads several speculations. Have the men structure physics or psychics more prepared? Do they develop activities more prone to contact? Does the reason of advanced contact is related to our male-dominated society?

Table 5: Information from ETI received in the authentic CE5thK $(n=25)$

\begin{tabular}{|c|c|c|}
\hline $\begin{array}{l}\text { Information from } \\
\text { ETI }\end{array}$ & Subcategory & n (\%) \\
\hline \multirow[t]{5}{*}{ Origin of ETI $(n=25) *$} & $\begin{array}{l}\text { Planet or satellite } \\
\text { from Solar System }\end{array}$ & $10(40.0 \%)$ \\
\hline & $\begin{array}{l}\text { Constellation of our } \\
\text { galaxy }\end{array}$ & $8(32.0 \%)$ \\
\hline & Unknown planet & $9(36.0 \%)$ \\
\hline & $\begin{array}{l}\text { Other galaxy or } \\
\text { dimension }\end{array}$ & $10(40.0 \%)$ \\
\hline & Not informed & $3(12.0 \%)$ \\
\hline Motivations of visiting & Study & $17(68.0 \%)$ \\
\hline \multirow[t]{5}{*}{ Earth $(n=25) *$} & exploration mission & \\
\hline & Alert to mankind & $19(76 \%)$ \\
\hline & Nuclear hazard & $15(60.0 \%)$ \\
\hline & $\begin{array}{l}\text { Awakening } \\
\text { consciousness }\end{array}$ & $19(76.0 \%)$ \\
\hline & Not informed & $2(8.0 \%)$ \\
\hline $\begin{array}{ll}\text { Knowledge } & \text { of } \\
\text { specific points: } \S & \end{array}$ & & \\
\hline \multirow{3}{*}{$\begin{array}{l}\text { Vegetarianism as } \\
\text { pattern recommended } \\
(\mathrm{n}=19)\end{array}$} & Yes & $16(84.2 \%)$ \\
\hline & $\begin{array}{l}\text { Consumption of } \\
\text { meat permitted }\end{array}$ & $1(5.3 \%)$ \\
\hline & $\begin{array}{l}\text { Consumption } \\
\text { fish permitted }\end{array}$ & $2(10.5 \%)$ \\
\hline \multirow{2}{*}{$\begin{array}{l}\text { Critics to capitalism or } \\
\text { money-based system } \\
(n=18)\end{array}$} & Yes & $18(100 \%)$ \\
\hline & Not & 0 \\
\hline \multirow{2}{*}{$\begin{array}{l}\text { Reincarnation as real } \\
\text { phenomenon }(n=12)\end{array}$} & Yes & $12(100 \%)$ \\
\hline & Not & 0 \\
\hline \multirow{2}{*}{$\begin{array}{l}\text { Presence of } \\
\text { among us }(n=15)\end{array}$} & Yes & $15(100 \%)$ \\
\hline & Not & 0 \\
\hline
\end{tabular}

*Origins of ETI or motivations of visiting the Earth could be more than one.

$\S$ In spite of total number of authentic CE5thK cases was 25 , in these variables the information was not available for all.

The first contact could occur starting from infancy all the way to middle adulthood and in $88.0 \%$ of cases, the contact phenomenon repeated one or more times. The last finding could mean a kind of preferential relation built with the authentic 'contactee'. We can find a similarity with our researcher of animals applying the sensitization that is a non-associative learning process in which repeated administrations of a stimulus results in the progressive amplification of a response [34].

In spite these authentic CE5thK cases are considered a world phenomenon we found that there was predominance in South America as origins of 'contactees'. This could be explained in part by the geographical proximity of the project and superior availability of information sources. However we cannot discard other reasons such as richness in natural resources or presence of historic and archeological sites located on this continent. The relative high rate of immigrants $(40.0 \%)$ in authentic CE5thK cases compared with a general population (3.1\% according $2008 \mathrm{UN}$ [35] lead to speculate that those experimenting an inter-cultural situation are more probably to have an advanced contact with ETI.

According to the information given by the ETI, there are different kinds of civilizations with several places of origin even planets or satellites within our Solar System. Furthermore, the motivation of coming ETI to the Earth were diverse and this could explain the different patterns of physical appearance, shapes of spacecraft and behavioral observed in the reported advanced contact with them [36].

The analysis of the information received by 'contactees' showed strong concordance among some specific variables of information received and this itself could mean a new a complementary criterion that could reinforce the status of authenticity of each other.

With respect to scientific validity of some specific information such as "telepathy", "vegetarianism", "money-critics" and "reincarnation" new discoveries are confirming this. Telepathy is a modern and recognized phenomenon studied by several researchers [37]. Vegetarianism is clearly more beneficial than an occidental or conventional diet with respect to prevention and treatment of chronic diseases of high morbidity and mortality as diabetes mellitus [38], cardiovascular diseases [39, 40] and cancer [41] and even, recently it was shown than longevity in vegetarians is higher than omnivorous subjects $[42,43]$. The consumption of fish even also can offer any protection and lower mortality by cardiovascular disease [44].

Critics of capitalism or money-based systems were existent from several centuries ago by great thinkers and philosophers [45]. The modern economic crisis that affects America and Europe mainly from 2008 could reflect again a reality of a system destined to implode [46]. The reincarnation and the subsequent concept of life after death is a scientific matter studied by several researchers that believe that indeed is a real phenomenon [47, 48, 49]. We also show that in these three variables most individuals on Earth live under a different pattern than most of extraterrestrial civilizations. The 
affirmative that ETI are among us is amazing information. This could lead us to believe that these ETI are very alike as us or that they had developed a technology or science able to transform themselves as metamorphosis with the appearance of a human being like certain animals here on the Earth as octopuses or chameleons.

We must consider that the information provided by authentic 'contactees' in the CE5thK from ETI could not necessarily be true or valid in part or all of the content. We could speculate that if the "Zoo hypothesis" were correct [50] the ETI would test our reactions and behaviors in face of the phenomenon.

We found no case considered as inconclusive evidence. This category was created when a case apparently seems authentic but lacking any objective criterions which would give a proof of authenticity.

The cases considered as "low probability" to be authentic were the most. In the practice we consider theses alleged CE5thK cases as not-happening or false. Among them, there are individuals very well known in the local and international circles of ufology and spiritualism. The explanations of what was happening in these cases would have different causes. We think that some of the proposed mechanism to explain the abduction (CE4thk) as non-extraterrestrial phenomenon could be working here as: possibility of to be the result of hoax, delusion or psychosis enhanced imagery [51] due to temporal lobe liability that within specific contexts can facilitate the creation of memories [52] false memory syndrome [53] or fantasy [54]. The meaning of our findings for these cases is that advanced contact probably is not true. The importance of these findings of these alleged non-authentic 'contactees' affirming having had a true CE5thK is in the fact these people lead a great number of followers and readers creating disinformation and leading an eventual debunking of the real possibility of true CE5thK, when it indeed probably happens as we are showing in this research.

\section{Limitations and straightness}

We must acknowledge several limitations to our study. First, our approach to determine whether a CE5thK is authentic has not a gold standard of reference to validate externally our findings. We only can imagine a time machine to verify what happened in the place and data alleged in each alleged contact with ETI. Due to nature non-reproducible of phenomenon, it is more next to criminal fact. On the other hand, internally the setting of objective criterions worked as validation of authenticity when the alleged CE5thK met all the subjective criterions. We admit that our conclusion about authenticity is only probabilistic as high or low. Additionally, due to a dynamic nature of appearance of new source of information of data about the cases CE5thK irrespective of categorization, we leave open the eventual possibility that any of these cases could change of categorization with the appearance of new evidences.

Second, in spite of intent to decrease at the least the subjectivity, setting the 12 criterions-rule of evaluation, it remained a degree of subjectivity in the scoring of subjective criterions as discussed above because the nature of matter studied and the component qualitative of study design. The consensus about the final categorization of two or more independent researchers lowers at least this bias.
At third, most of the members of the team were ufologist, with the probable bias of give more believing than skepticism to the stories perhaps resulting in higher scoring in order to cut the level of high probability of authenticity. This would not be a limitation, because, we must understand that like a cardiologist is takes a recommended professional in order to perform a guideline about cardiovascular disease diagnosis, so a ufologist is recommended in order to perform this type of study because the expertise and domain in the field.

The straightness of our work is in the fact of finding a significant number of authentic CE5thK cases that proved our hypothesis. An eventual polemics or critics on validity of results must be directed individually on each case.

\section{Implications for our society}

Our study begun from the opposite line of reasoning from the scientific institutions that aim to find ETI like as the Search for Extraterrestrial Intelligence (SETI) [55] via some form of astronomical observation, usually in the radio frequency range, with the aid of radio telescopes assuming that the first contact had not yet happened. Recently in the Economic Forum Davos 2013 it was predicted that the discovery of ETI as one of five "X factors" - emerging concerns of possible future importance and with unknown consequences- would certainly be one of the biggest news stories and interest would be intense. The discovery's largest near-term impact would likely be on science itself [56]. In this sense the information about social-economical organization, type of recommended food or other kind of knowledge identified in our study, definitely could challenge key paradigms in several fields of science and knowledge. The analysis more deeply of these true CE5thK cases merits additional research. New studies will be necessary to get a better understanding and meaning of the phenomenon of advanced extraterrestrial contact.

\section{CONCLUSION}

Using an original approach, we found evidence to support that advanced contact from ETI with human beings probably is happening on the Earth at present. Future studies will confirm these findings in other places of the world. Additionally in these authentic CE5thK cases, there are important and revolutionary information with amazing potential for our society in several fields of knowledge.

\section{ACKNOWLEDGMENT}

Dr. Julio Acosta-Navarro thanks to Prof. Moacyr Nobre and Luiza Gouveia for the chance of discuss the study design; to Paulo Giordano, Aguinaldo Triumpho, Jose Rigamonti, Vera Graça, Priscila Ozaki, Marcos Bento Jr, Alan Costa, Rose Castro, Lincoln Rancan, Divair dos Santos, Claudio Santos, and Rosangela Lopes for helpful discussions about the CE5thK cases; to Alexander Senna, Ilze Campos and Belkis Retuerto for technical assistance; to Rafael Curi, Luis Gedo, Paulo Mesquita, Edson Capazzolli, Mauro de Rezende, Nilson Cicone, Edson and Neuza Brillante for help in field research in Brazil; and finally to Silvia Cárdenas-Prado, Julio Dongo, Jaime Valdivia and Hugo Acosta (in memoriam) for help in field research in Peru. 


\section{Extraterrestrials Contact Human Beings: An Original Approach To Set The Authenticity of Alleged Close Encounters of The Fifth Kind}

\section{REFERENCES}

[1] Valleé J. Anatomy of a Phenomenon: UFOs in Space. Ballantine Books, Toronto, Canada, 1965

[2] Bramley W. The Gods of Eden. Avon Books, New York, 505 p, 1989.

[3] Haqq-Misra JD. \& Baum SD. The Sustainability Solution to The Fermi Paradox, JBIS, 2009; 62: 47-51.

[4] Condon E. Scientific study of unidentified flying objects. Bantan Books/University of Colorado, Colorado, United States, 1969.

[5] Boffey P. UFO Study: Condon group find no evidence of visits from outer space. Science, 1969; 163: 260-262.

[6] Hart MH. Explanation for the Absence of Extraterrestrials on Earth. Quarterly Journal of the Royal Astronomical Society, 1975; 16:128-135.

[7] Tipler F. Extraterrestrial intelligent beings do not exist. Quarterly Journal of the Royal Astronomical Society 1980; 21:267-281.

[8] Kolosimo P. Astronaves en la Prehistoria. Edit. Plaza-Janés, Barcelona, 1976.

[9] Freitas, R. Extraterrestrial Intelligence in the Solar System: Resolving the Fermi Paradox. Journal of the British Interplanetary Society, 1983; 36:496-500.

[10] Baun SD, J. Haqq-Misra, Domagal S. Would contact with extraterrestrials benefit or harm humanity? A scenario analysis. Acta astronautica, 2011; 68: 2114-2129.

[11] Dudas E. Theory and phenomenology of type I strings and M-theory. Clas Quant Grav, 2000; 17: R41-R116.

[12] Drake F. Extraterrestrial Intelligence. Science, 1993; 260: 474-475.

[13] Berliner, D. \& Huneeu, A. UFO Briefing Document - The best available evidence. UFO Research Coalition, United States, 1995.

[14] McNally RJ, Clancy SA. Sleep Paralysis, Sexual Abuse, and Space Alien Abduction. Transcultural Psychiatry, 2005; 42 (1): 113-122.

[15] Bartholomeu, R.; Basterfield K \& Howard G. UFO abductees and contactees: psychopathology or fantasy proneness? Professional Psychology: Research and Practice, 1991; 22: 215-222.

[16] Hynek JA. The UFO experience. A Scientific Enquiry. Henry Regnery, Chicago, 1972.

[17] Bryan C. Close Encounters of fourth kind. Alien abduction, UFOs, and the Conference at M.I.T. Knopf, New York, 1995.

[18] Imbrogno P \& Horrigan M. Contact of the 5th kind. Llewellyn Pub. Minnesosta, 261 p, 1997.

[19] Acosta-Navarro, J. (2009) El Síndrome del Capitalismo: prognóstico reservado. Vitko Novi, el Tomás Moro de nuestros tiempos. Edit. Mantaro, Lima, 310p. 2009.

[20] Tong A, Sainsbury P, Craig J. Consolidated criteria for reporting qualitative research (COREQ): a 32-item checklist for interviews and focus groups. Int J Qual Health Care, 2007, 19 (6): 349-357.

[21] Sahakian W \& Sahakian ML. Ideas of the Great Philosophers. Barnes and Noble. ISBN 1-56619-271-4, 1993.

[22] Frances A, Kahn D, Carpenter D et al. A new method of developing expert consensus practice guidelines. Am J Manag Care, 1998; 4:1023-9.

[23] Jones TD. The diagnosis of rheumatic fever. JAMA, 1944; 126 (8): $481-4$

[24] Paz S. Contacto Interdimensional. Los guias hablan de nuevo. Errepar, Buenos Aires, 413 p. 1994.

[25] Benitez, J. OVNIS: SOS a la humanidad. Plaza \& Janes editorial, Barcelona, 232 p. 1976.

[26] Piacenza, G. Extraterrestrial contact and integral theory. Exopolitics Journal 4 (1) March 2012: 39-73.

[27] Paz S. El libro de los guardianes y vigilantes de mundos. Errepar, Buenos Aires. 167 p. 1998

[28] Casellato R \& Steven W. UFO contact from Klermer planet. 2002.

[29] Reis H. Experiências conscientes fora do corpo. São Paulo. http://www.gnosisonline.org/wp-content/uploads/2010/08/Experien cias-Conscientes-Fora-do-Corpo-Herminio-Reis.pdf. 2009

[30] Oliveira M. As possibilidades do infinito. São Paulo, Edit Kópion, 162 p. 1987.

[31] Target Group Index, IBOPE. Dia Mundial do Vegetarianismo: 8\% da população brasileira afirma ser adepta do estilo. 01/10/2012. http://www.ibope.com.br/pt-br/noticias/paginas/dia-mundial-do-veg etarianismo-8-da-populacao-brasileira-afirma-ser-adepta-ao-estilo.a spx. Accessed 28 February 2014

[32] World Population 2013. United Nations Statistical Division. http://data.worldbank.org/indicator/SP.POP.TOTL. Accessed 28 February 2014

[33] Pew Research Center's Forum on Religion \& Public Life (2010). A Report on the Size and Distribution of the World's. Major Religious Groups as of 2010.

http://www.pewforum.org/2012/12/18/global-religious-landscape-exe c/. Accessed 28 February 2014
[34] Shettleworth SJ. Cognition, Evolution and Behavior (2nd Ed) New York:Oxford, 2010.

[35] United Nations Department of Economic and Social Affairs (UN DESA), Trends in International Migrant Stock (2008). http://esa.un.org/migration/index.asp?panel=1.

[36] Ribera A. Platillos volantes en Iberoamérica y España. Plaza-Janés, Barcelona, 1976

[37] Venkatasubramanian G. et al. Investigating paranormal phenomena: Functional brain imaging of telepathy. Int J Yoga, 2008; 1:66-71.

[38] Tonstad S. Vegetarian diets and incidence of diabetes in the Adventist Health Study-2. Nutr Metab Cardiovasc Dis, 2013; 23:292-299.

[39] Duo L. Effect of the vegetarian diet on non-communicable diseases. J Sci Food Agric, 2013, DOI: 10.1002/jsfa.6362.

[40] Huang T. et al. Cardiovascular disease mortality and cancer incidence in vegetarians: a meta-analysis and systematic review. Ann Nutr Metab, 2012; 6:233-240.

[41] Tantamango-Bartley Y, Jaceldo-Siegl K, Fan J et al. Vegetarian diets and the incidence of cancer in a low-risk population. Cancer Epidemiol Biomarkers Prev, 2013; 22:286-294.

[42] Singh PN, Sabate J, Fraser GE. Does low meat consumption increase life expectancy in humans? Am J Clin Nutr, 2003, 78: 526S-32S.

[43] Orlich M.J. et al. Vegetarian dietary patterns and mortality in Adventist Health Study 2. JAMA Intern Med, 2013; 173:1230-1238

[44] Ka H. et al. Accumulated Evidence on Fish Consumption and Coronary Heart Disease Mortality. A Meta-Analysis of Cohort Studies. Circulation, 2004; 109: 2705-2711.

[45] Engels F. Historical Materialism - Socialism: Utopian and Scientific. New York Labor News, New York, 1901.

[46] Amin S. The Implosion of Contemporary Capitalism. Books, New York, 2013

[47] Nagaraj AK, Nanjegowda RB, Purushothama SM. The mystery of reincarnation. Indian J Psychiatry, 2013; 55:S171-176.

[48] Lucchetti G, Santos L, Lucchetti AL et al. Rare medical conditions and suggestive past-life memories: a case report and literature review. Explore (NY), 2013; 9:372-376.

[49] Tucker JB. Children's reports of past-life memories: a review. Explore (NY), 2008; 4: 244-8.

[50] Ball JA. The Zoo Hypothesis. Icarus, 1973; 19(3): 347-349.

[51] Ballester-Olmos VJ. Alleged Experiences Inside UFOs: An Analysis of Abduction Reports. Journal of Scientific Exploration, 1994; 8: 91-105.

[52] Persinger MA. Neuropsychological profiles of adults who report "sudden remembering" of early childhood memories: implications for claims of sex abuse and alien visitation/abduction experiences. Percept Mot Skills, 1992; 75:259-266.

[53] Dittburner TL. \& Persinger MA. Intensity of amnesia during hypnosis is positively correlated with estimated prevalence of sexual abuse and alien abductions: implications for the false memory syndrome. Percep Mot Skills, 1993; 77: 895-898

[54] Spanos NP, Burgess ChA, Burgess MF. Past-Life Identities, UFO Abductions, and SRA: The Social Reconstruction of Memories. Intern J Clin Exper Hypnosis, 1994; 42: 433-446.

[55] Hisashi H. An Encounter with extraterrestrial intelligence. Biol Sci Space, 2003; 17: 324-340.

[56] World Economic Forum . Global Risks 2013 Eighth Edition. An Initiative of the Risk Response Network http://www3.weforum.org/docs/WEF_GlobalRisks_Report_2013.pdf Accessed 28 February 2014

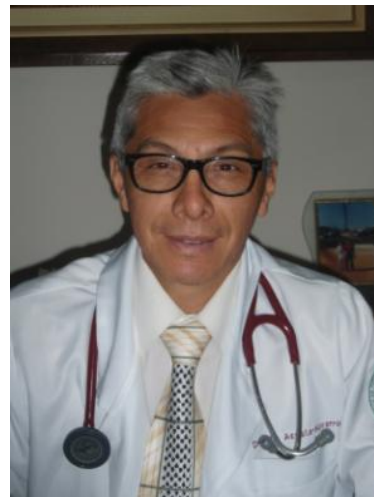

Julio Acosta-Navarro, MD, PhD, PhD. Peruvian-Brazilian scientist. He is a Medica Doctor by the "Universidad Nacional Federico Villarreal", Lima, Perú (1992) and Clinic Cardiologist by the "Universidad Mayor de San Marcos", Lima, Perú (1997). $\mathrm{He}$ also became Specialist in Clinical Cardiology by the "Brazilian Society of Cardiology" (1998), Intensive Care Medicine by the "Brazilian Association of Intensive Care Medicine" (2000), Clinical Nutrition by the "Brazilian "Brazilian Society of Clinical Nutrition" (2000), and Internal Medicine by the "Brazilian Society of Internal Medicine" (2002). He got his first Doctorate $(\mathrm{PhD})$ in Biological Sciences at the Heart Institute of the School of Medicine, University of São Paulo (2002) researching the association of type of diet and risk factors of cardiovascular disease. Visiting Professor at 
international events such as PAHO / WHO ("Impacto de la protección patentaria sobre el acceso de medicinas", Brasilia, Brazil, 2004), "Instituto de Cardiologia y Cirugia Cardiovascular de La Habana", Cuba, 2007 ), "University of Loma Linda" (5th and 6th International Congress on Vegetarian Nutrition, California, USA, 2008 and 2013 respectively), "World Intellectual Property Organization” (WIPO), São Paulo, Brazil, 2010, and "Justus-Liebig University" (Giessen, Germany, 2014). He is author of several papers and books about matters of science-frontiers and reviewer of scientific journals as "The American Journal of Cardiology", "CLINICS", and "PLOS ONE" among others. Interested in social issues of the world, he got his second Doctorate $(\mathrm{PhD})$ in Social Sciences by the "Programa de Integração de América Latina" of University of São Paulo (2011) researching the repercussions of TRIPS Agreement about Intellectual Property on access to medicines for critical diseases. At present, he is Professor Collaborator and leads the "CARVOS Project" at level of Post-Doctorate in the Heart Institute of Sao Paulo University researching the relation of vegetarian diet with the prevention of chronic diseases and its influence on several biological processes. 